\title{
Paleorrelevo pleistocênico e estimativas de dissecação vertical e volumétrica para o Holoceno em uma pequena bacia hidrográfica - médio vale do Rio Paraíba do Sul (RJ) Pleistocenic paleo-surface and vertical and volumetric denudation estimates for Holocene in a small catchment - middle valley of Paraíba do Sul River (RJ)
}

\section{André Souza Pelech}

\author{
Instituto Brasileiro de Geografia e Estatística
} aspelech@gmail.com

\begin{abstract}
Resumo
O médio vale do rio Paraíba do Sul é marcado por diversos episódios de preenchimentos dos fundos de vale e reencaixamento da drenagem. Dentre esses episódios, o evento Manso caracteriza uma grande instabilidade na paisagem durante o início do Holoceno que gerou intensos processos erosivos nas encostas. A remobilização de sedimentos foi tão intensa, que os canais fluviais não tiveram competência para transportá-los, ocasionando um entulhamento generalizado tanto nos vales fluviais quanto nas cabeceiras de drenagem. Estudos na bacia do ribeirão dos Três Poços, tributária do rio Paraíba do Sul, estimaram que os depósitos sedimentares relacionados ao entulhamento correspondem a um volume entre 13 e 18 milhões de metros cúbicos, e mesmo após episódios de reencaixamento da drenagem, aproximadamente $70 \%$ desse volume ainda se encontra preservado dentro da bacia. $\mathrm{O}$ presente estudo teve como objetivos a identificação o paleorrelevo anterior ao evento Manso e a avaliação do volume sedimentar erodido principalmente durante o evento Manso. O paleorrelevo foi obtido por uma interpolação das cotas altimétricas de topos e linhas de cumeada, através de procedimentos semi-automatizados em ambiente SIG. O estudo estimou que o volume sedimentar remobilizado durante o evento Manso foi entre 100 e 230 milhões de metros cúbicos, e apenas uma quantia entre $6,5 \%$ e $15 \%$ deste montante foi responsável pelo entulhamento generalizado da paisagem durante o Holoceno.
\end{abstract}

Palavras Chave: paleorrelevo; dissecação vertical e volumétrica; Médio Vale do rio Paraíba do Sul

\begin{abstract}
The middle valley of Paraíba do Sul river is marked by several episodes of bottom valley fills and deposits cut by drainage. Among these episodes, the Manso event features a large instability in the landscape during the early Holocene that generated intense erosion on the slopes. The remobilization of sediment was so intense, that river channels had no capacity to carry them, causing widespread filling both in river valleys and in drainage headwaters. Studies in the Três Poços catchment, a tributary basin of the Paraíba do Sul river, estimated that the sedimentary deposits related to the filling episode correspond to a volume between 13 and 18 million cubic meters, and even after the episodes of deposits cut, approximately $70 \%$ of this volume is still preserved within the basin. This study aimed to identify the previous paleo-surface preceding Manso event and assess the volume sediment eroded mainly during the same event. The paleo-surface was obtained by an interpolation of altimetry values from the tops and ridge lines, through semi-automated procedures in a GIS environment. The study estimated that the volume sediment remobilized during Manso event was between 100 and 230 million cubic meters, and only an amount between $6.5 \%$ and $15 \%$ of this amount was responsible for the widespread landscape filling during the Holocene.
\end{abstract}

Keywords: paleo-surface; vertical and volumetric denudation; Middle Valley of Paraíba do Sul River

\section{Introdução}

A dinâmica de estocagem de sedimentos vem sendo estudada ao longo das últimas décadas em diversas pesquisas no Médio Vale do rio Paraíba do Sul. Tais estudos fornecem hoje um excelente panorama dos depósitos quaternários regionais e sua evolução ao longo do Quaternário tardio diante de episódios de acumulação sedimentar intercalados a reencaixamentos da drenagem.

Moura \& Mello (1991) sintetizam a aloestratigrafia dos depósitos quaternários da região de Bananal (SP), identificando os mesmos através da morfoestratigrafia. $\mathrm{O}$ registro estratigráfico identifica um grande episódio de instabilidade na paisagem durante o início do Holoceno, onde houve intensos processos erosivos nas 
encostas. Essa remobilização de sedimentos foi tão intensa que os canais fluviais não tiveram competência para transportá-los, gerando um entulhamento generalizado nos fundos de vale. Os depósitos sedimentares relacionados a este evento são reconhecidos como a Aloformação Manso, e são associados ao nível de terraço alto, identificado regionalmente. Posteriormente a este episódio, houve um ciclo de entalhamento (incisão fluvial) e geração de novos níveis de terraços.

Recentemente alguns estudos têm tentado quantificar, através de estimativas volumétricas, o montante de material sedimentar remobilizado nesses eventos quaternários. Barros et al. (2007) e Pelech (2013) estimaram o balanço sedimentar holocênico através do mapeamento dos depósitos quaternários em pequenas bacias hidrográficas no Médio Vale do rio Paraíba do Sul.

Diversos estudos direcionados à identificação de superfícies aplainadas, como Ferraz \& Valadão (2006), vêm abordando o paleorrelevo, utilizando pontos cotados dos topos, e suas formações superficiais associadas, para gerar um perfil altimétrico que corresponderia grosseiramente ao relevo original antes da dissecação. Motoki et al. (2008), Aires et al. (2012), dentre outros, utilizam uma técnica de análise de paleorrelevo denominada seppômen, onde a área é dividida em grades (linhas verticais e horizontais igualmente espaçadas) que formam retângulos, de onde são extraídos os pontos de maior cota altimétrica. Esta corrente de estudos mais recentes vem sendo muito útil para identificação de atividade neotectônica e também episódios de aplanamentos antigos.

O presente estudo, realizado em uma pequena bacia hidrográfica do Médio Vale do rio Paraíba do Sul, pretende simular alguns modelos de paleorrelevo, assim como sua evolução até o relevo encontrado atualmente, introduzindo uma metodologia semiautomática para a estimativa vertical e volumétrica do significativo episódio erosivo (evento Manso) que entulhou a paisagem no início do Holoceno. Os resultados deste estudo contribuem para a melhor compreensão do balanço sedimentar desta bacia, complementando os levantamentos realizados por Pelech (2013). Para isto, foram utilizadas ferramentas de geoprocessamento que facilitem a reprodução em outras bacias hidrográficas da região. Tal técnica visa a contribuir também para os estudos de dissecação de relevo.

\section{Objetivos}

Este estudo tem como objetivo principal a obtenção dos volumes envolvidos na retomada erosiva associada ao evento Manso na bacia hidrográfica do Ribeirão dos Três Poços, situada no Médio Vale do rio Paraíba do Sul. Para isto, a pesquisa foca na simulação dos cenários de paleorrelevo pré-holocênico, e na posterior evolução para o relevo atualmente existente. Desta forma, pretende-se obter a topografia dos cenários de paleorrelevo pré-holocênico, e a dissecação entre este paleorrelevo e o relevo atual, em termos de profundidade (dissecação vertical) e de volume sedimentar (dissecação volumétrica).

\section{3. Área de estudo e breve caracterização geológico- geomorfológica}

A área de estudo desta pesquisa é a bacia hidrográfica do ribeirão dos Três Poços, afluente direto do rio Paraíba do Sul. A bacia se localiza na fronteira entre os municípios de Volta Redonda e Pinheiral, no estado do Rio de Janeiro (figura 1).

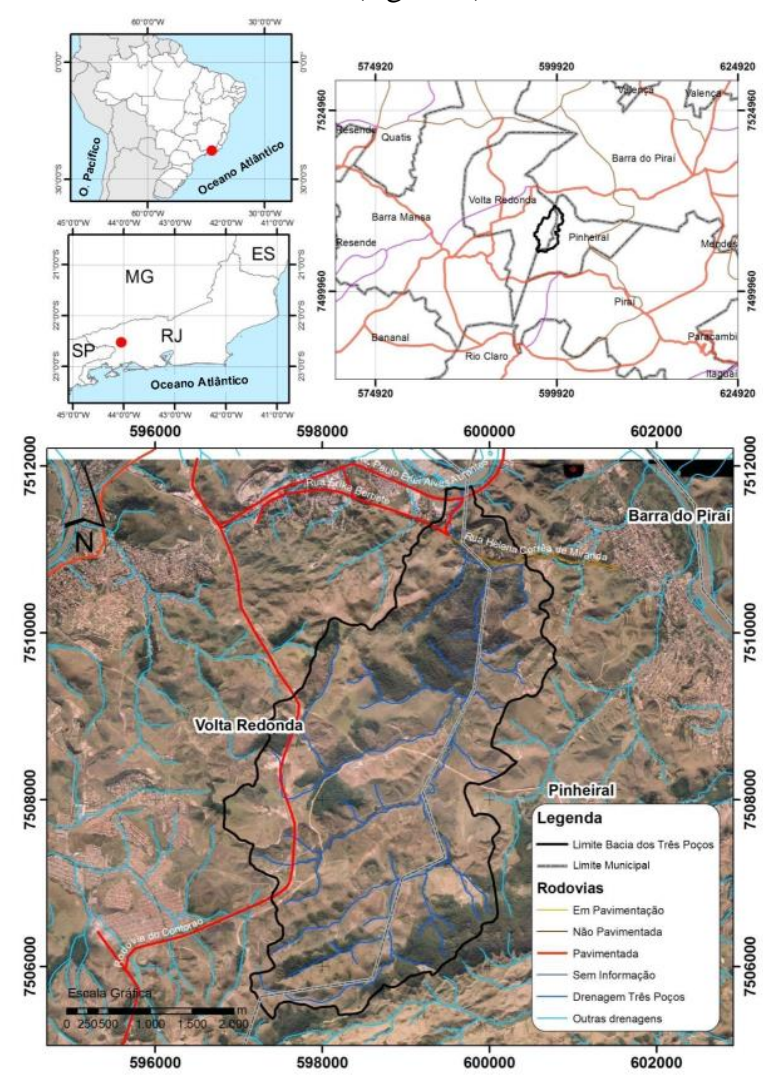

Figura 1: Mapa de localização da bacia hidrográfica do Ribeirão dos Três Poços. Mapas do Brasil e do estado do Rio de Janeiro em coordenadas geográficas, South American Datum 1969. Mapa municipal e da bacia em projeção UTM, datum WGS 1984, fuso 23S. Fonte: IBGE (2007) e IBGE (2009).

A bacia hidrográfica do Ribeirão dos Três Poços está inserida na região da bacia sedimentar de Volta Redonda, abrangendo o gráben da Casa de Pedra, local de importante sedimentação paleogênica. O mapa geológico da CPRM (2007), na escala 1:100.000, identificou apenas a Formação Resende no gráben, mas sabe-se que nos topos dos morros e colinas da bacia de Volta Redonda é encontrada a Formação Pinheiral, conforme Sanson (2006). As falhas normais delimitadoras do gráben possuem direção NE-SW. Segundo CPRM (2007), dentro da bacia do Ribeirão dos Três Poços a litologia do embasamento cristalino é representada pelo Granito Resgate, a sul do gráben, e por silimanita gnaisse bandado, a norte do gráben. A figura 2 apresenta o mapa geológico da Bacia de Volta Redonda, realizado por Sanson (2006), e a localização da bacia hidrográfica. 


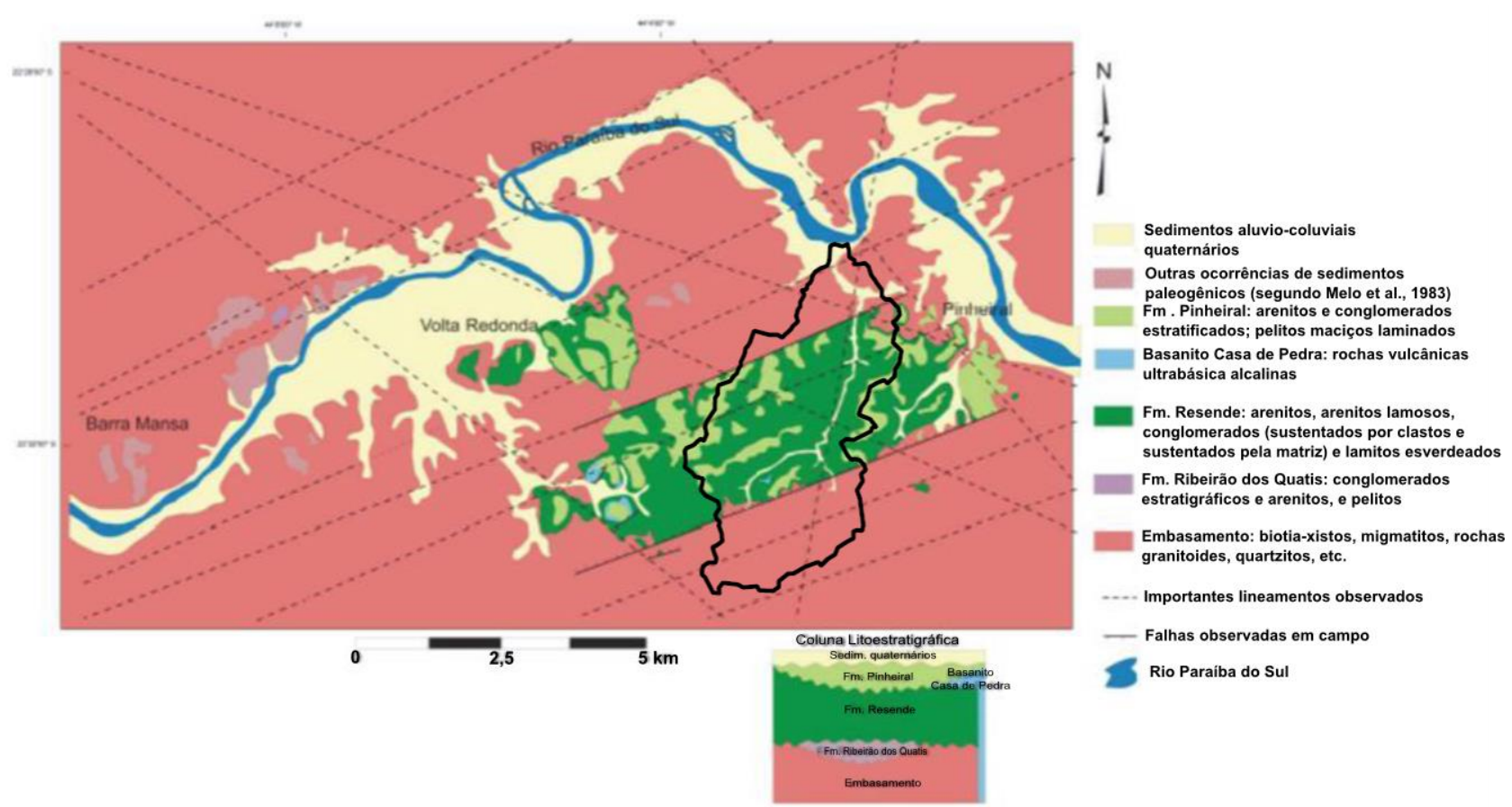

Figura 2: Mapa geológico da Bacia de Volta Redonda (modificado de Sanson 2006). Em preto, os limites da bacia hidrográfica do Ribeirão dos Três Poços.

Mello et al. (2005), em estudo mais detalhado, apresentaram os seguintes domínios geológicogeomorfológicos para a Bacia de Volta Redonda (e que são encontrados na bacia do Ribeirão dos Três Poços):

- Planície fluvial da bacia de Volta Redonda: depósitos sedimentares do rio Paraíba do Sul, de idade quaternária;

- Morros em degraus topográficos sobre substrato cristalino: compartimentos de morros dissecados, compondo degraus. As estruturas do embasamento cristalino controlam os compartimentos de orientação NE-SW, e situam-se entre a planície fluvial do rio Paraíba do Sul e as colinas do Gráben Casa de Pedra;

- Colinas do Gráben da Casa de Pedra: colinas suaves e pouco dissecadas, desenvolvidas sobre os depósitos paleogênicos que preenchem o gráben. $\mathrm{O}$ contato entre o embasamento cristalino e o gráben, representado pelas falhas normais, tem repercussão forte na topografia das encostas e vales, formando áreas onde as drenagens são estranguladas ("gargantas").

No médio vale do rio Paraíba do Sul, a reconstituição do arcabouço sedimentar com base na definição de unidades limitadas por descontinuidades - unidades aloestratigráficas - e dentro de uma perspectiva morfoestratigráfica - enfatizando a relação genética entre o depósito e a forma topográfica, como propõem Meis \& Moura (1984) - permitiu identificar várias fases de encaixamento fluvial e remodelamento das encostas (Moura \& Mello 1991, Moura et al. 1991). Moura \& Mello (1991) propuseram uma coluna estratigráfica para a região de Bananal, porém representativa regionalmente.

O principal evento holocênico registrado (Aloformação Manso) foi responsável pelo entulhamento generalizado dos vales fluviais, ainda hoje preservado na morfologia pela expressão espacial significativa do nível de terraço fluvial mais elevado (T1) e pelas feições de cabeceiras e sub-bacias entulhadas. Segundo Mello (1992), houve um grande episódio erosivo que produziu grande quantidade de sedimentos, que excedeu a capacidade dos cursos fluviais para transportá-los, sendo, então, progressivamente entulhados (fácies Campinho), o que elevou o nível de base local, provocando a retenção de sedimentos coluviais cada vez mais próximos da área fonte (fácies Fazendinha) e o preenchimento dos canais erosivos por materiais de natureza alúvio-coluvial (fácies Quebra-Canto). A magnitude desse suprimento sedimentar foi responsável pela desarticulação das cabeceiras de drenagem em anfiteatro em relação às calhas fluviais, visto que os fundos de vale sofreram um entulhamento generalizado (Peixoto 1993).

Pelech (2013) mapeou as feições deposicionais e erosivas da bacia do Ribeirão dos Três Poços (figura 3), e calculou o balanço sedimentar associado ao preenchimento dos fundos de vale e reencaixamento da drenagem durante o Holoceno. $\mathrm{O}$ autor estimou que a deposição relacionada ao evento Manso ficou entre 13 e 18 milhões de metros cúbicos, sendo a maior parte estocada no médio curso da bacia hidrográfica do Ribeirão dos Três Poços, nos domínios do gráben Casa de Pedra. Os episódios erosivos subsequentes ao evento Manso remobilizaram aproximadamente 30\% dos depósitos entulhados, com esvaziamento mais significativo registrado no baixo curso, onde houve uma remoção aproximada de $50 \%$ dos sedimentos.

\section{Materiais e métodos}

Primeiramente, é importante ressaltar que todos os materiais utilizados nesse estudo são gratuitos e estão 
disponíveis na internet. Quanto aos procedimentos técnicos, foi utilizado o software ArcGis 10, no entanto, os métodos aqui apresentados poderão ser replicados em outros Sistemas de Informações Geográficas (SIG).

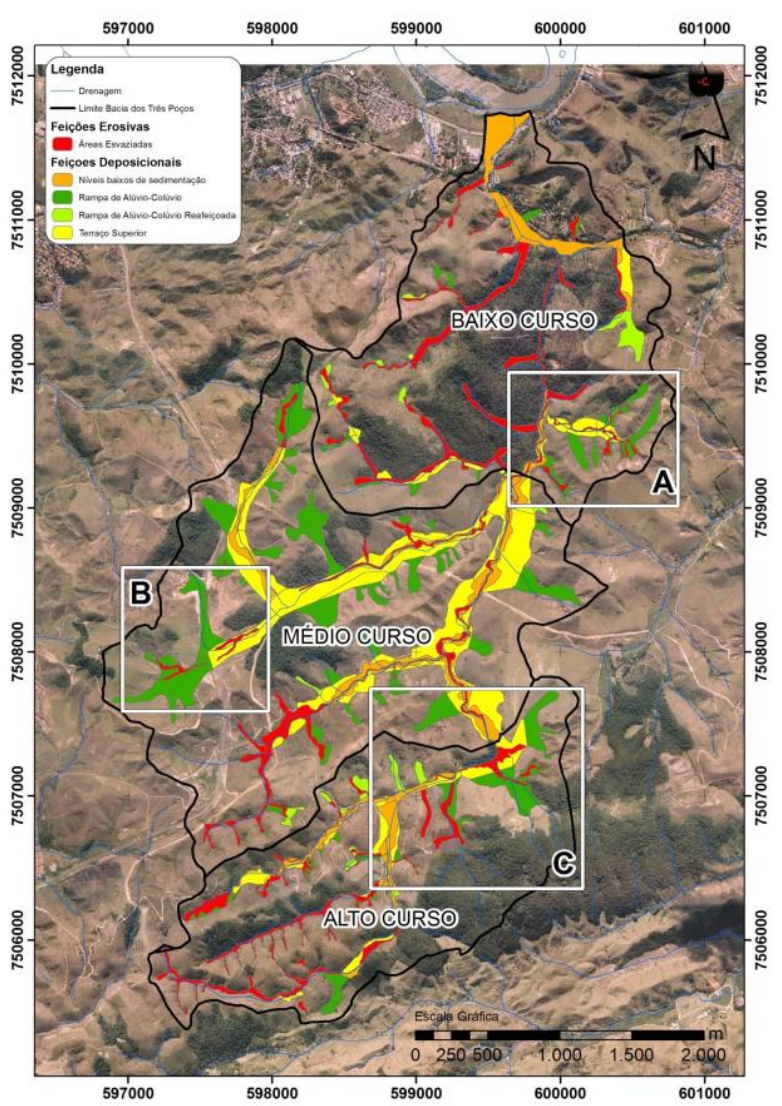

Figura 3: Mapa de feições deposicionais e erosivas da bacia do Ribeirão dos Três Poços (Pelech 2013). As drenagens se apresentam deslocadas, e sem precisão cartográfica, devido à escala de origem do vetor. Os levantamentos sedimentológicos dos depósitos holocênicos deste estudo foram realizados pelo autor nos retângulos em destaque (A, B e C).

Para a simulação dos cenários de paleorrelevo préholocênico, partiu-se da premissa da amostragem dos pontos de topo e das linhas de cumeada do relevo atual - nos moldes dos estudos referentes às superfícies aplainadas - assumindo-se que tais pontos tratam-se de remanescentes do paleorrelevo. Para isto, foi obtido no site do IBGE o Modelo Digital de Elevação (MDE), na escala de 1:25.000, para a bacia em questão. É importante destacar que o IBGE disponibiliza todo o MDE para o estado do Rio de Janeiro nesta escala, podendo-se, desta forma, replicar, validar ou questionar o método aqui apresentado em futuras ocasiões.

Para a obtenção dos pontos de topo e de linhas de cumeada sem a necessidade de um esforço manual, foram executadas algumas operações de análise espacial em ambiente SIG. O arquivo do MDE trata-se de um raster, ou seja, uma matriz com valores altimétricos em cada pixel. Existem duas ferramentas no software ArcGis 10 denominadas flow direction (direção de fluxo) e flow accumulation (acumulação de fluxo), que determinam, respectivamente, a direção do fluxo superficial e os locais de acumulação.
Geralmente, essas duas ferramentas combinadas geram um arquivo matricial com a rede hidrográfica, que pode ser detalhada ou grosseira, conforme os parâmetros utilizados ao rodar as ferramentas. Neste caso, o objetivo era a obtenção das áreas de topo e de linhas de cumeada, e para isto, o MDE original foi invertido, ou seja, todos os valores dos pixels foram multiplicados por '-1'. Ao inverter os valores dos pixels, o MDE também se torna invertido e, desta forma, as áreas de acumulação de fluxo corresponderiam espacialmente às áreas de topos e de linhas de cumeada, conforme ilustra o esquema da figura 3.

Após a obtenção dos pixels relacionados aos topos e linhas de cumeada, estes foram associados aos valores de cota altimétrica do MDE original, através de uma ferramenta de extração por máscara ('extract by mask' no caso do ArcGis 10). Esse novo arquivo matricial foi então interpolado espacialmente com o intuito de se simular o paleorrelevo existente na transição do Pleistoceno e Holoceno. Para isto foram simulados três cenários de paleorrelevo correspondentes aos diferentes métodos de interpolação existentes, que, no caso, foram o IDW (inverse weighted distance), a krigagem $\mathrm{e}$ o spline. A utilização de diferentes métodos de interpolação permite compreender o comportamento das variáveis utilizadas diante das interpolações e suas diferenças.

Segundo o manual do software Arcgis 10.2, o método IDW é uma interpolação que estima os valores das células pelas médias dos pontos de dados amostrais na vizinhança para cada célula processada. Quanto mais próximo um ponto está do centro de uma célula sendo estimada, maior a influência, ou peso, no processo de cálculo da média.

A krigagem é um método geoestatístico avançado que gera uma superfície estimada de um arranjo de pontos dispersos. Trata-se de um método que exige um melhor conhecimento do comportamento espacial do fenômeno. No presente estudo, foram utilizados os parâmetros padronizados (default) com a finalidade de se conhecer as respostas do interpolador.

O método spline trata-se de um método que estima valores utilizando uma função matemática que minimiza a curvatura de superfície total, resultando em uma superfície suave que passa exatamente pelos pontos amostrados.

Como última etapa deste roteiro metodológico, temse a obtenção da dissecação volumétrica através da operação matemática de subtração. Desta forma, subtrai-se os valores do arquivo matricial do relevo atual (MDE original) diante dos valores do arquivo matricial do paleorrelevo interpolado. Esta diferença, realizada por pixel, é a dissecação vertical, dada em metros. Conhecendo-se a área de cada pixel foi possível a obtenção do volume e, portanto, a dissecação volumétrica.

\section{Resultados}

Como produto da inversão do relevo (multiplicação pelo valor '-1' em todos os pixels do MDE original) e 
subsequente uso das ferramentas de direção e acumulação de fluxos do software ArcGis 10, obtevese os pixels das áreas de topo e de linhas de cumeada, conforme mostrado na figura 3. Através da figura 4 se tem uma ideia melhor de quais áreas foram extraídas do MDE original, representado pelas curvas de nível com equidistância de 5 metros. Nota-se claramente que as ombreiras - que em determinadas situações são consideradas como resquícios de sedimentação pleistocênica - são representadas por estes pixels extraídos.

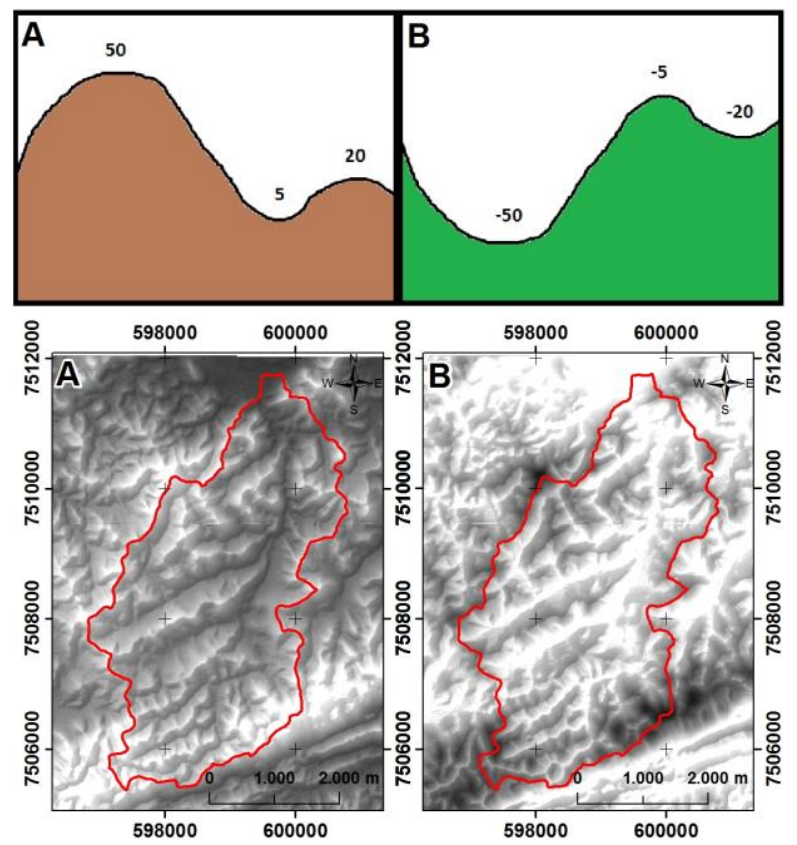

Figura 4: A ilustração do lado esquerdo (A) mostra um perfil topográfico hipotético obtido do MDE original. Os números referemse a cotas altimétricas hipotéticas. Conforme explicado, no lado esquerdo a acumulação de fluxo se daria na área da cota 5, correspondente aos vales fluviais reais existentes. Após a inversão da topografia (multiplicação por '-1'), nota-se que nos locais onde outrora encontravam-se topos e linhas de cumeada (A), agora encontram-se áreas rebaixadas (B). Desta forma, em B a acumulação de fluxos se daria nas áreas das cotas '-50' e '-20', que correspondem espacialmente às áreas de topo e de linhas de cumeada do MDE original. Abaixo das ilustrações encontram-se o MDE original e o invertido correspondentes, onde a escala de cores vai do preto (pixels com valores baixos) ao branco (pixels com valores altos). Em vermelho, os limites da bacia hidrográfica.

Neste arquivo matricial de topos e linhas de cumeada, foram associadas as cotas altimétricas dos pixels do MDE original e, desta maneira, foi possível executar as interpolações espaciais.

O relevo atual, representado pelo MDE do IBGE, e os paleorrelevos interpolados na presente pesquisa são encontrados na figura 5. Em linhas gerais, verifica-se que a interpolação por IDW ( $B$ na figura 5 ) e por krigagem ( $C$ na figura 5 ) - usado no padrão default do software ArcGis 10.2 - apresentaram resultados bastante semelhantes. Nestes dois interpoladores houve uma agregação significativa das protuberâncias de relevo, de modo que topos e linhas de cumeada, contíguas no relevo atual, tenderam a se aglutinar em uma única feição de maior porte nos relevos interpolados. Desta forma, em ambos os cenários, as drenagens se apresentam bem mais escassas que no relevo atual.

Por outro lado, a interpolação pelo método spline $(D$ na figura 5) não aglutinou tantas protuberâncias de relevo quanto os outros métodos. Neste interpolador, a topografia ainda mostra bastante semelhança ao relevo atual, pois a superfície gerada passa exatamente pelos pontos (cotas) interpolados. É possível notar uma tendência de geração de formas suavizadas através deste método.

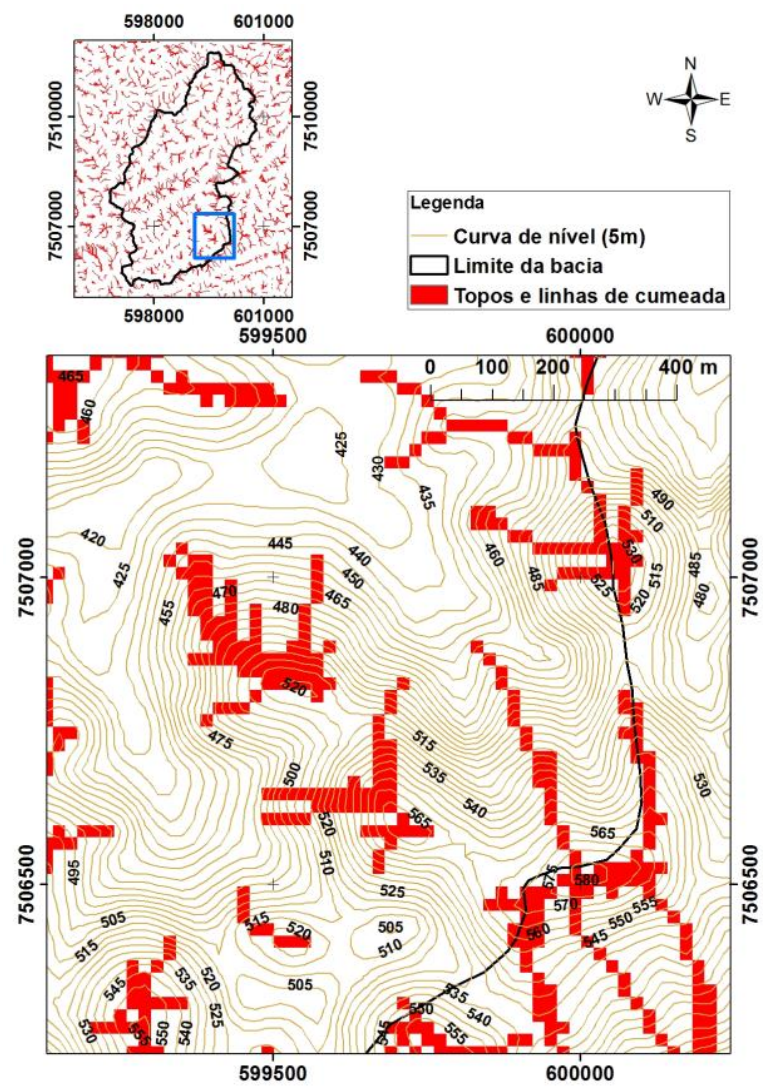

Figura 5: Detalhamento na área sudeste da bacia do ribeirão dos Três Poços (polígono azul). Pixels dos topos e das linhas de cumeada extraídos pelas ferramentas de direção e acumulação de fluxos no MDE invertido, em ambiente SIG. Notar que estes pixels contemplam trechos de ombreira. Bacia do ribeirão dos Três Poços

Como forma de mostrar o comportamento de cada método de interpolação nos vales fluviais, foram traçados alguns perfis topográficos transversais à direção dos vales. Os locais dos perfis podem ser encontrados na figura 6 e os perfis propriamente na figura 7. Nota-se claramente que os métodos IDW e krigagem apresentaram um comportamento bastante semelhante. Verifica-se que em ambos os métodos, o palerrelevo simulado apresenta uma grande diferença altimétrica com relação ao relevo atual. Alguns vales se apresentam em um nível bastante superior ao nível atual, como pode ser observado nos perfis B-B', C-C', D-D', E-E' e F-F'. No perfil A-A' a diferença altimétrica é tamanha, que os atuais vales seriam interflúvios nos paleorrelevos simulados.

O método spline, conforme dito anteriormente, confirma-se como um modelo muito similar ao relevo 
atual. Nos perfis A-A' e B-B' a mudança nas formas de relevo é bastante sutil. Os perfis C-C', D-D' e E-E' mostram comportamentos razoáveis para uma estimativa de paleorrelevo.

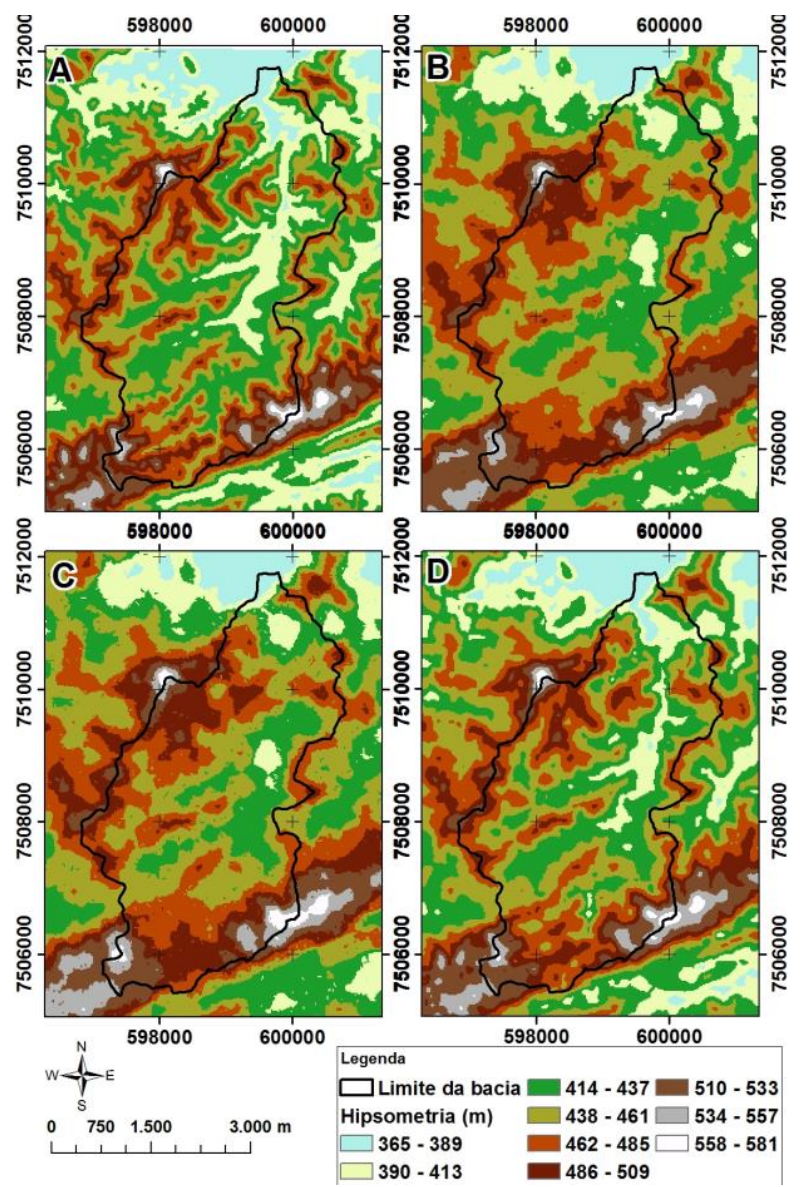

Figura 6: Relevo atual e paleorrelevos interpolados a partir das cotas dos topos e das linhas de cumeada. A: relevo atual; B: paleorrelevo interpolado por IDW; C: paleorrelevo interpolado por krigagem; D: paleorrelevo interpolado por spline.

O perfil F-F', situado no baixo curso da bacia, em um dos altos estruturais da Bacia Sedimentar de Volta Redonda, atualmente se trata de um vale encaixado em ' $\mathrm{V}$ ', conforme mostrado no perfil topográfico referente ao relevo atual. Dificilmente a paleotopografia deste perfil poderia ser aquelas simuladas pelos métodos IDW e krigagem, isto porque trata-se da "saída" da bacia, num local onde provavelmente não houve grande acumulação sedimentar. Desta forma, neste perfil F-F' o método spline provavelmente é o mais próximo do paleorrelevo real, isto porque a dissecação no local foi exercida sobre rochas sãs.

O médio curso da bacia é representado pelo Gráben da Casa de Pedra, local onde se encontram significativos depósitos paleogênicos da Bacia Sedimentar de Volta Redonda. Os perfis topográficos do relevo atual traçados neste ambiente (B-B', D-D' e E-E') se apresentam mais suaves (em 'U' ou em fundo chato) que os perfis traçados nos alto e baixo cursos (A-A', e F-F'), onde se encontram os altos estruturais da bacia e rochas cristalinas. O perfil C-C', por estar situado transversalmente à falha normal do gráben, de direção NE-SW, mostra claramente a transição entre aos depósitos paleogênicos, a noroeste, e as rochas cristalinas, a sudeste.

Conforme já anunciavam os paleorrelevos simulados e os perfis traçados, houve uma grande diferença na dissecação entre os métodos IDW e krigagem, de um lado, e spline, de outro (figura 8). Os métodos IDW e krigagem apresentaram uma dissecação muito mais profunda, mostrando um esvaziamento significativo do alto e baixo curso da bacia do ribeirão dos Três Poços. O setor mais preservado, correspondente ao médio curso da bacia, é exatamente no Gráben da Casa de Pedra.

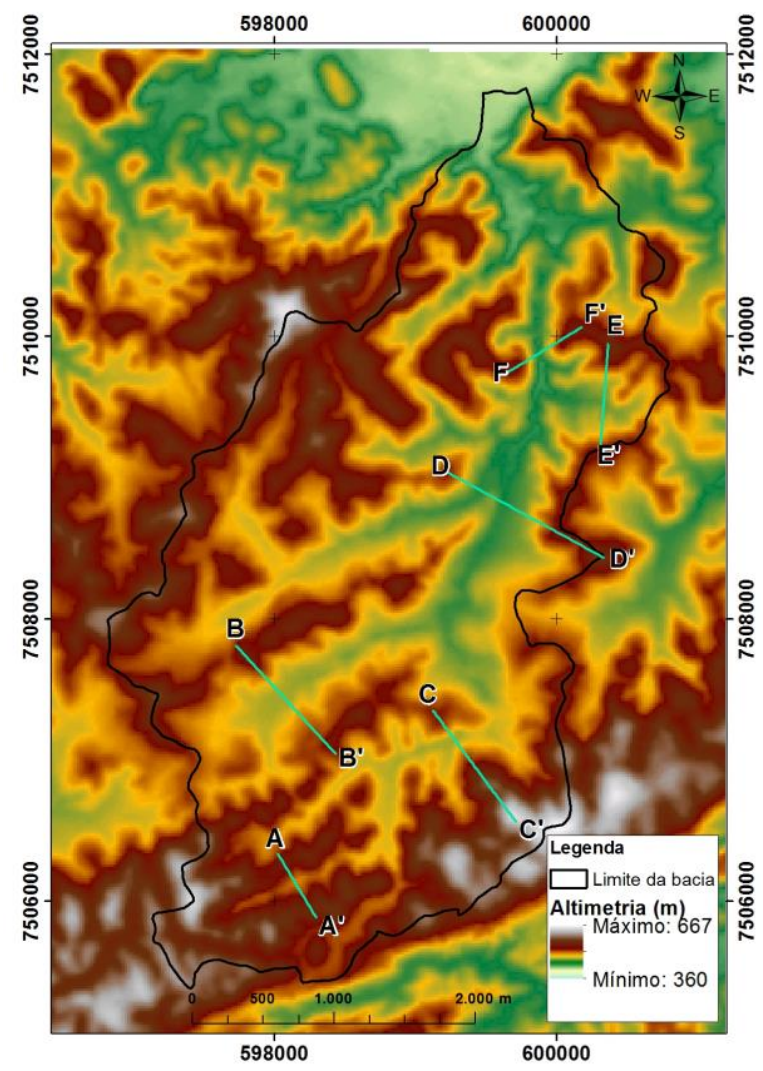

Figura 7: Relevo atual, representado pelo Modelo Digital de Elevação disponibilizado pelo IBGE. Em verde, os perfis topográficos transversais aos vales.

$\mathrm{O}$ método spline mostrou um comportamento geral semelhante aos outros, com dissecação mais evidente no alto e baixo curso e um menor esvaziamento no médio curso. No entanto, a dissecação, no que tange às profundidades, se apresenta bem menor que nos outros métodos.

A dissecação volumétrica, obtida através da multiplicação das áreas das células pela profundidade da dissecação, foi estimada para cada método. O método spline apresentou a menor dissecação volumétrica, aproximadamente 85 milhões de metros cúbicos, enquanto que os métodos IDW e krigagem apresentaram 200 e 215 milhões de metros cúbicos, respectivamente. Como não se tem evidências concretas do paleorrelevo anterior ao evento Manso, é prudente considerar que a dissecação volumétrica da 
bacia após o evento Manso possa estar entre 85 e 215 milhões de metros cúbicos.
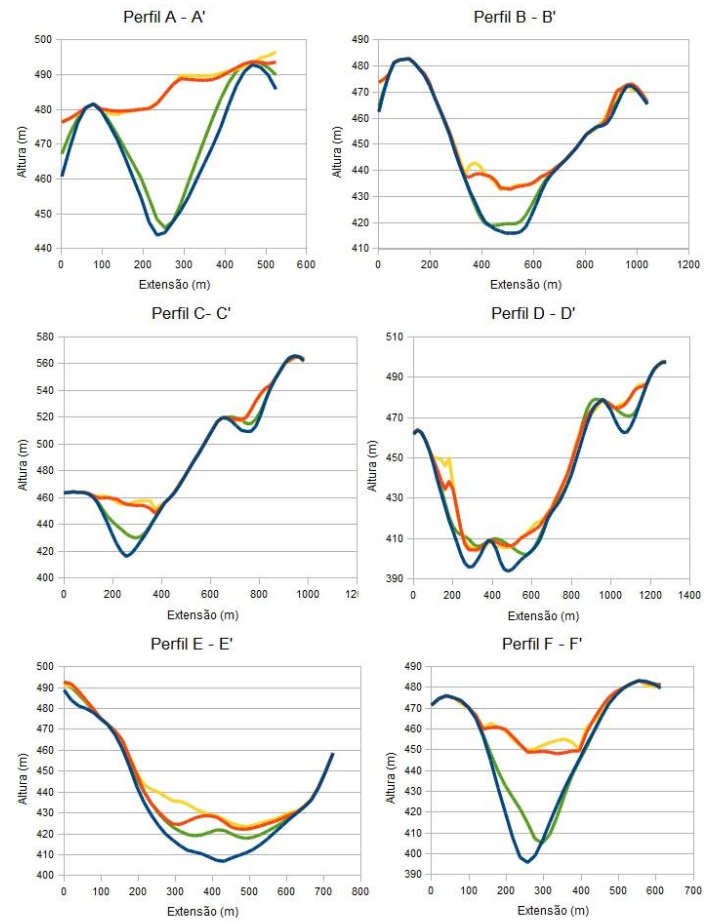

Legenda - Relevo Atual

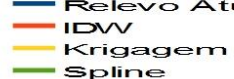

Figura 8: Perfis topográficos transversais aos vales fluviais. Os locais dos perfis podem ser encontrados na figura 7 .

Conforme dito anteriormente, Pelech (2013) estimou um volume entre 13 e 18 milhões de metros cúbicos para o entulhamento gerado ao final do evento Manso. No entanto, a dissecação volumétrica aqui apresentada não engloba este valor, visto que os cálculos foram realizados em relação à superfície atual e, desta forma, foram consideradas as cotas de topo destes depósitos quaternários encontrados nos terraços e rampas de alúvio-colúvio. Logo, deve-se se somar o volume do entulhamento aos valores da dissecação volumétrica, onde o resultado seria a dissecação volumétrica efetiva total, e o volume do entulhamento seria apenas o que ficou na bacia. Portanto, utilizando-se uma média aproximada dos valores, chega-se a um valor de 15 milhões de metros cúbicos para o entulhamento e, desta forma, tem-se uma dissecação volumétrica entre $100 \mathrm{e}$ 230 milhões de metros cúbicos, onde um valor entre $15 \%$ e $6,5 \%$ destes montantes teriam permanecido na bacia ao final do evento Manso.

\section{Conclusões e discussões}

A presente pesquisa apresentou um novo método, semi-automático, para a análise de paleorrelevos. Este método garante que as cotas de relevo amostradas para a interpolação se situem efetivamente nos interflúvios, sejam eles topos ou linhas de cumeada. Trata-se de uma vantagem em relação ao método Seppômen.

Ressalta-se que para estudos específicos de mapeamento de profundidade de dissecação, como os modelados de dissecação mapeados pelo IBGE (IBGE, 2009), pode ser interessante utilizar a rede irregular triangular (triangular irregular network - TIN) para a interpolação dos pontos de cota altimétrica amostrados, pois se trataria apenas de medir o desnível entre o interflúvio e a drenagem.

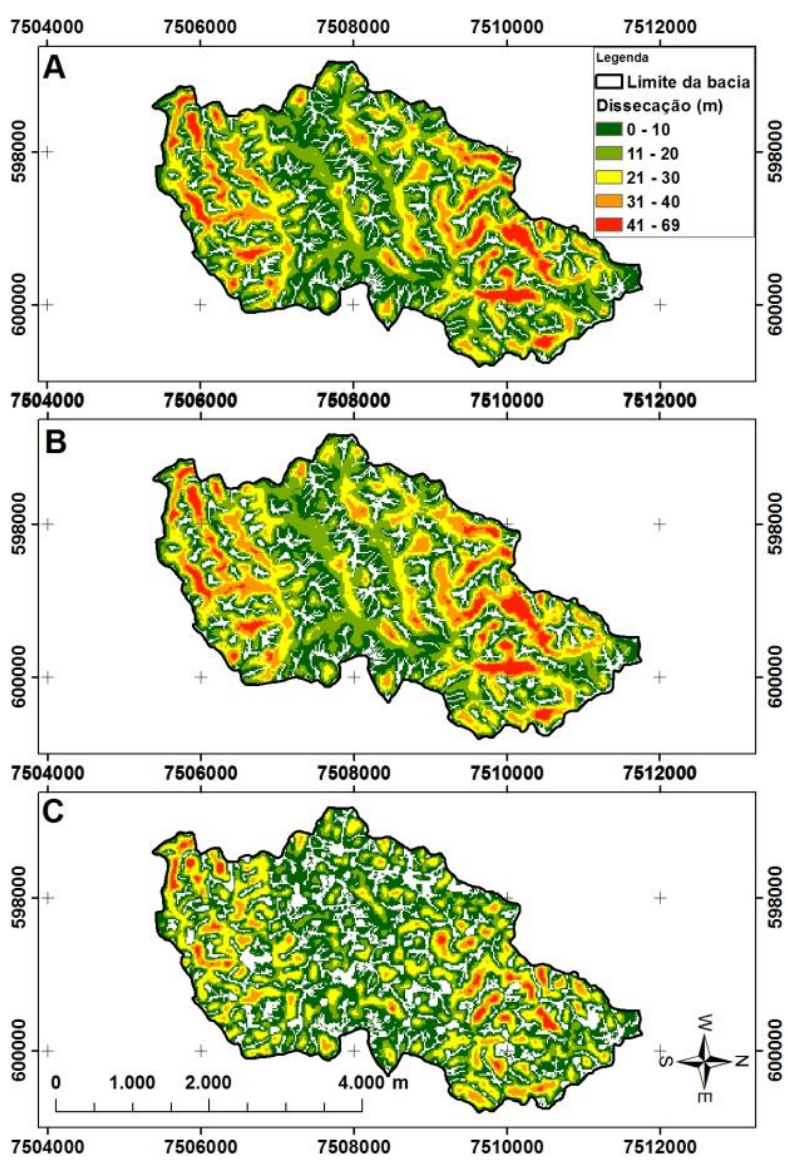

Figura 9: Mapa de dissecação vertical pelos métodos IDW (A), krigagem (B) e spline (C).

Os cálculos de volume realizados entre os modelos de paleorrelevo e o relevo atual mostraram uma significativa dissecação volumétrica, com valores que estão entre 100 e 230 milhões de metros cúbicos. Pelech (2013) identificou que durante a primeira fase de remobilização dos depósitos entulhados - que corresponde ao encaixamento da drenagem, surgimento do terraço alto e deposição dos níveis inferiores de sedimentação - apenas cerca de $15 \%$ dos sedimentos permaneceram na bacia. $\mathrm{Na}$ ocasião o autor utilizou esta proporção de $15 \%$ de sedimentos que ficaram na bacia para $85 \%$ que conseguiram alcançar o rio Paraíba do Sul, e estimou, grosseiramente, um valor em torno de 80 e 110 milhões de metros cúbicos para a remobilização de sedimentos do evento Manso. Como pode ser observado, estes valores estão de acordo com a estimativa volumétrica do presente estudo correspondente ao método de interpolação spline. Isto não quer dizer que os valores máximos calculados no presente estudo, que giram em torno de 230 milhões de metros cúbicos, não possam ter ocorrido. Deve-se considerar que a transição entre o Pleistoceno e o Holoceno é marcada pela transição global de um 
período glacial, de clima mais seco, para um período interglacial, de clima mais úmido nas regiões tropicais. Moura \& Mello (1991) retratam o evento Manso como um grande episódio de instabilidade na paisagem, e que o registro estratigráfico associado (Aloformação Manso), possui uma importante responsabilidade na conformação das formas de relevos que são encontradas atualmente. Somado a isso, tem-se a fase tectônica de extensão NW-SE, associada ao Holoceno (Sanson 2006) que pode ter movimentado as falhas normais do gráben da Casa de Pedra. Essa movimentação pode ter gerado um novo desnível entre o gráben e seus altos estruturais, e gerando por consequência um episódio erosivo. Nesta hipótese, o gráben teria atuado como uma área de retenção de sedimentos e, em razão das características morfológicas, e por estar em um nível mais rebaixado, não sofreu uma dissecação tão profunda.

Atualmente existe uma crescente preocupação com a aceleração de alguns processos ambientais em razão das atividades antrópicas. É interessante, sob este ponto de vista, observar que, em um cenário recente, sem uma ocupação humana significativa, os processos erosivos atuantes no Médio Vale do rio Paraíba do Sul foram de uma magnitude talvez ainda não observada nos dias de hoje.

\section{Referências}

Aires J.R., Motoki A., Motoki K.F., Motoki D.F., Rodrigues J.G. 2012. Análises geomorfológicas do Platô de Teresópolis e da Serra do Mar, RJ, com o auxílio de Seppômen e ASTER GDEM e sua relação aos tectonismos cenozóicos. Anuário do Instituto de Geociências - UFRJ, 35(2):105-123

Barros S. C., Pelech A.S., Peixoto M.N.O. 2007. Avaliação da Produção de Sedimentos em Cabeceiras de Drenagem entulhadas na Sub-bacia do Córrego Resgate (Bananal, SP). In: X Simpósio de Geologia do Sudeste, Diamantina, Livro de Resumos, p.151.

CPRM - Companhia de Pesquisa de Recursos Minerais 2007. Mapa geológico (Folhas Volta Redonda e Santa Rita de Jacutinga). Escala 1:100.000. Disponível em: http://www.cprm.gov.br.

Ferraz C.M.L., Valadão R.C. 2006. A tectônica cenozóica e a evolução do relevo: das "Chapadas" do Jequitinhonha à Planície Costeira do Sul da Bahia. In: VI Simpósio Nacional de Geomorfologia, Goiânia, Anais do congresso.

IBGE - Instituto Brasileiro de Geografia e Estatística 2007. Folha 2743-2 NE. Rio de Janeiro, Modelo Digital de Elevação, Escala 1:25.000. Disponível em: http://www.ibge.gov.br.

IBGE - Instituto Brasileiro de Geografia e Estatística 2009a. Base cartográfica integrada ao Milionésimo. 2009a. Rio de Janeiro, Escala 1:1.000.000. Disponível em: http://www.ibge.gov.br.

IBGE - Instituto Brasileiro de Geografia e Estatística 2009b. Manual Técnico de Geomorfologia. Segunda edição. Rio de Janeiro, 182p. Disponível em: http://www.ibge.gov.br.

Mello C.L. 1992. Fácies Sedimentares, Arquitetura Deposicional e Relações Morfoestratigráficas em um Sistema de Leques Aluviais Holocênicos: Aloformação Manso- Médio vale do rio Paraíba do Sul (SP/RJ). Dissertação de Mestrado, Programa de Pós-Graduação em Geografia, Instituto de Geociências, Universidade Federal do Rio de Janeiro, 188p.

Mello E.V., Peixoto M.N.O., Silva T.M., Moura J.R.S. 2005. Evolução da rede de drenagem e transformações tecnogênicas nos canais fluviais em Volta Redonda (RJ), médio vale do Paraíba do Sul. 2005. In: X Congresso da Abequa - I Encontro Brasileiro do Tecnógeno, Guarapari, Boletim de resumos.

Meis M.R.M., Moura J.R.S. 1984. Upper Quaternary Sedimentation and Hillslope Evolution: Southeastem Brazilian Plateau. Amer. Joum. of Science, 284:241-254.
Motoki A., Petrakis G.H., Sichel S.E., Cardoso C.E., Melo, R.C., Soares R.S., Motoki K.F. 2008. Landform origin of the Mendanha Massif, State of Rio de Janeiro, Brazil, based on the geomorphological analyses by summit level map technique. Geociências, 27(1):99-115.

Moura J.R., Mello C.L. 1991. Classificação Aloestratigráfica do Quaternário Superior na Região de Bananal(SP/RJ). Revista Brasileira de Geociências, 21(3):236-254.

Moura J.R.S., Peixoto M.N.O., Silva T.M. 1991. Geometria do relevo e estratigrafia do quaternário como base à tipologia de cabeceiras de drenagem em anfiteatro - médio vale do rio Paraíba do Sul. Revista Brasileira de Geociências, 21(3):255265.

Peixoto M.N.O. 1993. Estocagem de sedimentos em cabeceiras de drenagem em anfiteatro: Médio Vale do rio Paraíba do Sul (SP/RJ). Dissertação de Mestrado, Programa de Pós-Graduação em Geografia, Instituto de Geociências, Universidade Federal do Rio de Janeiro, 192p.

Pelech A.S. 2013. Balanço sedimentar holocênico da bacia hidrográfica do ribeirão dos Três Poços - Volta Redonda/Pinheiral (RJ). Dissertação de Mestrado, Programa de Pós-Graduação em Geografia, Instituto de Geociências, Universidade Federal do Rio de Janeiro, 138p.

Sanson M.S.R. 2006. Sistemas Deposicionais Aluviais e Tectônica Rúptil Cenozóica na Região de Volta Redonda (RJ): Rift Continental do Sudeste do Brasil. Dissertação de Mestrado, Programa de Pós-graduação em Geologia, Instituto de Geociências, Universidade Federal do Rio de Janeiro, 142p.

Recebido 06 de agosto de 2015 Aceito 02 de agosto de 2016 